Acta Universitatis Wratislaviensis • No 3982

Literatura i Kultura Popularna XXV, Wrocław 2019

https://doi.org/10.19195/0867-7441.25.5

\title{
Rafal Kochanowicz
}

ORCID: 0000-0003-0378-0455

Uniwersytet im. Adama Mickiewicza w Poznaniu

\section{Game lore — dodatek, podstawa i ,granica" supersystemów}

Słowa kluczowe: game lore, kultura popularna, gry komputerowe, supersystemy rozrywkowe lar culture

Keywords: game lore, popular culture, computer games, entertainment supersystems of popu-

\section{Lore - fenomen kultury fanowskiej}

Termin game lore w odniesieniu do gier komputerowych nie ma spolszczenia - funkcjonuje analogicznie jak na przykład nazwa fantasy i równocześnie pozostaje, podobnie jak ona, nie do końca sprecyzowany. Najbliżej zakresu znaczeniowego lore byłyby jednak polskie pojęcia odwołujące się bezpośrednio do treści gier, choć niekoniecznie do ich mechaniki. Innymi słowy lore można najprościej określić jako swego rodzaju osnowę i kontekst do ujętej w grze akcji, przy zastrzeżeniu, że nie chodzi tylko o sam temat, lecz także o tę cechę, którą z kolei sugeruje angielskie znaczenie terminu — tradycję związaną z występowaniem danych wątków, stanowiącą dla graczy istotny kwalifikator, decydujący o zaliczaniu poszczególnych motywów do uniwersum ujętego w danej produkcji ${ }^{1}$. Elementy składające się na lore to zatem przede wszystkim zarys topografii, historii i genealogii oraz związki przyczynowo-skutkowe sankcjonujące tematyczny wymiar współtworzonych przez graczy wydarzeń.

1 Wypada zaznaczyć, że w pewnym stopniu — z zachowaniem wszelkich różnic i proporcji — zjawisko game lore mieści się w obszarze zjawisk określanych mianem tak zwanego cyberfolkloru. Jest bowiem także przejawem spontanicznie „praktykowanej” wiedzy graczy, dotyczącej danej komputerowej produkcji; por. Netlor. Wiedza cyfrowych tubylców, red. P. Grochowski, Toruń 2013. 


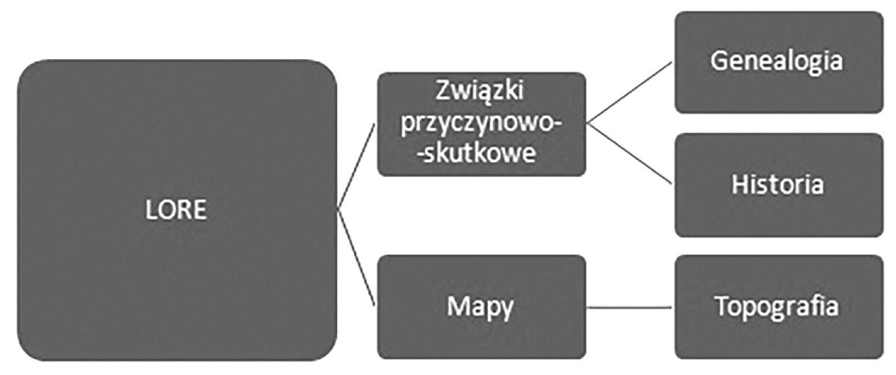

Schemat 1

Źródło: opracowanie własne.

Wypada jednak podkreślić, że choć o lore można mówić w odniesieniu do większości gier, to termin ten pojawia się najczęściej — co poniekąd oczywiste — w wypadku produkcji najbardziej rozbudowanych i fabularyzowanych. Ma on ponadto charakter konwencjonalny, mocno związany ze stylem odbioru i działalnością fanowską (świadectwa odbioru). Nierzadko to de facto sami miłośnicy danego tytułu wyznaczają granicę między tym, co należy do lore, a tym, co ich zdaniem jest unlore, czyli stanowi pierwiastek niepasujący do ukazanego w grze świata czy uniwersum, do którego twórcy produkcji nawiązali. Lore w grach nie zawsze jest bowiem autorskim dziełem programistów, scenarzystów czy grafików komputerowych. W tym też ujęciu — ze względu na proweniencję - można wyszczególnić dwa podstawowe typy omawianego zjawiska: lore zapożyczone, które w grze jest rozwijane — na przykład Star Wars: The Old Republic (2011, producent: BioWare, wydawca: LucasArts, Electronic Arts Inc.; dalej: SWTOR), Lord of the Rings Online (2007, producent: Turbine Inc, wydawca: Turbine Inc et al.; dalej: LOTRO), Age of Conan (2008, producent: Funcom, wydawca: Eidos, dystrybutor: CD Projekt), Wiedźmin (2007, producent: CD Projekt RED, wydawca: Atari/Infogrames, wydawca polski: CD Projekt) — oraz lore oryginalne, stworzone na potrzeby danej gry (najczęściej serii gier), które z kolei jest ekspansywne - na przykład serie „The Elder Scrolls”, „Gothic”, „Fallout” czy „World of Warcraft" (dalej też: WOW).

\section{Lore zapożyczone}

O pierwszym przypadku można mówić, gdy twórcy danej produkcji umieszczają akcję gry w fantastycznej rzeczywistości już dobrze znanej miłośnikom, na przykład w świecie Gwiezdnych wojen czy Tolkienowskim Śródziemiu, a fani w ramach interpretacji i niekiedy dyskusji analizują poszczególne motywy pod kątem ich zgodności z pierwowzorem i spójności na przykład z wcześniejszymi 
produkcjami tematycznie rozwijającymi zapożyczony świat. Można to między innymi zaobserwować, śledząc dyskusje graczy w SWTOR, które dotyczą nie tylko zgodności poszczególnych wątków z uniwersum George'a Lucasa, lecz także prawdopodobieństwa związków przyczynowo-skutkowych, jakie w aspekcie mechaniki MMORPG (ang. massively multiplayer online role-playing game) odsłaniane są w kolejnych dodatkach do gry (zob. ilustracja 1).

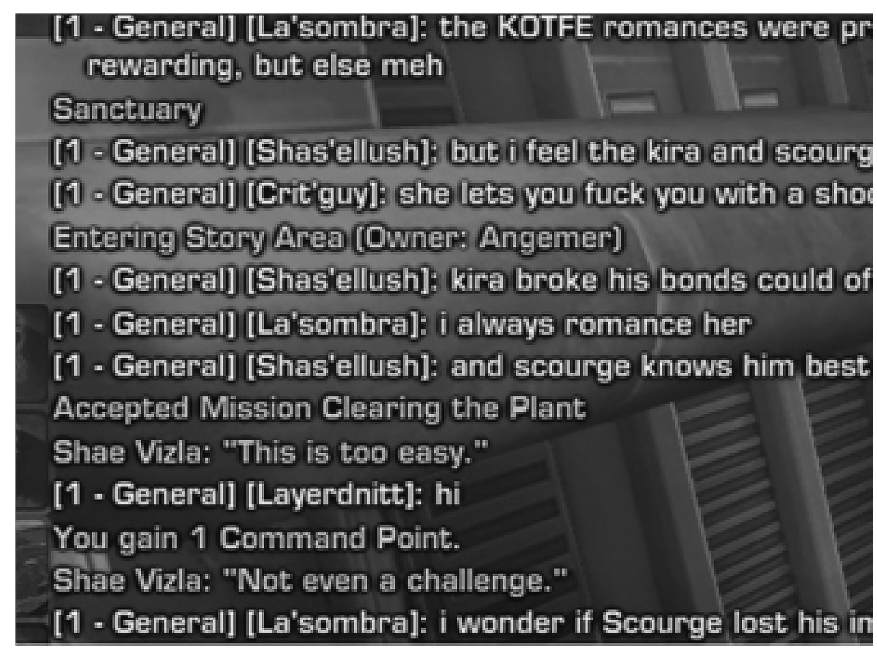

Ilustracja 1. Zrzut ekranu z dyskusji w SWTOR

Źródło: Star Wars: The Old Republic, 2011, producent: BioWare, wydawca: LucasArts, Electronic Arts Inc.

Sposób, w jaki twórcy gry tematycznie organizują ukazany świat, jest bowiem dla graczy ważny również ze względu na immersję. Ewentualne absurdy, brak uzasadnienia czy niekonsekwencje stają się unlore i burzą wrażenie zanurzenia w komplementarnym świecie gry. Wątpliwości mogą dotyczyć zarówno kwestii bardzo szczegółowych, choćby kondycja drugoplanowej postaci (na przykład uwidoczniony na zrzucie ekranu problem ,nieśmiertelności” jednego z Sithów — Lorda Scourge'a w SWTOR), jak i zagadnień fundamentalnych, na przykład klasa postaci w LOTRO:

Hobbit Warden - against lore?

My fresh-out-of-Shire Warden is a hobbit. It's my first serious try with the class, and I love it! And I particularly love being a powerful and sturdy hobbit. But it isn't really a lore-friendly combo, is it? Hobbits are more suited to be burglars or minstrels. Yet I am greatly enjoying my hobbit Warden, and would like some input on how it can - if possible - be lore-friendly ${ }^{2}$.

${ }^{2}$ Por. Hobbit Warden - against lore?, https://www.lotro.com/forums/showthread.php?480688Hobbit-Warden-against-lore (dostęp: 30.11.2016). 
Nie brakuje też rozważań analitycznych związanych z polską produkcją Wiedźmin 3: Dziki Gon (2015, producent: CD Projekt RED, wydawca: Bandai Namco Entertainment, wydawca polski: CD Projekt), która — szczególnie w środowisku rodzimych miłośników gier i twórczości Andrzeja Sapkowskiego — jest do dziś wnikliwie omawiana w kontekście relacji z literackim pierwowzorem:

Na pohybel kanonowi!

Przechodząc kolejne Wiedźminy, długo byłem przekonany, że deweloperzy po prostu zręcznie wykorzystali luki zostawione w książkach przez ich autora — albo dokonali minimalnej tylko korekty oryginalnych wydarzeń. Że wznowili pogoń Dzikiego Gonu (czy może raczej: Dearg Ruadhri, Czerwonych Jeźdźców) za Ciri, ustalając, iż tzw. Wyspa Jabłoni, na którą trafili Geralt i Yennefer po domniemanej śmierci, znalazła się w obrębie Spirali, po której Gon był w stanie podróżować pomiędzy światami. Ta jedna mała zmiana w zupełności uzasadniłaby, dlaczego nasza wiedźminka znowu znalazła się w niebezpieczeństwie ze strony Ludu Olch — musząc ujawnić się, by ratować swoich bliskich. Jednak CD Projekt RED postanowił znacznie bardziej namieszać w kanonie [wyr. oryg.] wykreowanym przez Sapkowskiego. Przede wszystkim zmieniono istotę Białego Zimna [... $]^{3}$.

Przytoczony cytat z fanowskiego artykułu oraz zaistniała pod jego wpływem dyskusja graczy na temat produkcji CD Projektu pozostają istotnymi świadectwami odbioru, niezbicie wskazującymi, że lore w grze dla najzagorzalszych miłośników tej formy rozrywki bywa nie mniej ważny niż gameplay (mechanika gry) czy aspekty audiowizualne. Twórcy danego tytułu, zapożyczając funkcjonujące już w kulturze wyobrażenia na temat fantastycznego uniwersum, prowokują dyskusje, ale też ryzykują, że ich propozycja zostanie przez graczy odrzucona jako niezgodna z konwencją.

Przykładem dużej ostrożności pod tym względem (a zarazem pomysłowości) jest sposób organizacji zapożyczonego lore w LOTRO. Twórcy gry nie powielają bowiem w całości pomysłów Tolkiena, lecz rozwijają te elementy, o których autor tylko wspominał bądź ich istnienie presuponowat ${ }^{4}$. Jedną z obszernych lokacji, jakie gracz może eksplorować, jest na przykład zaledwie wzmiankowana przez pisarza Forochel - śnieżne i mroźne tereny wzorowane w wersji cyfrowej na krajach skandynawskich (w szczególności na kolorycie Finlandii), zamieszkiwane przez społeczność Lossothów. Topograficzne rozwijanie pomysłów Tolkiena przypomina chciałoby się powiedzieć - wypełnianie barwami pustych konturów kolorowanki.

W podobny sposób twórcy LOTRO rozwinęli też — notabene całkowicie pominięte w filmach Petera Jacksona — motywy związane z Szarą Drużyną, która w prozie Tolkiena pojawia się na początku Powrotu króla i towarzyszy Aragornowi w wy-

3 Por. Draug, Gorzkie żale nad fabuła Wiedźmina 3 - tak dobra na tle innych gier, tak złą na tle ksiązek, https://gameplay.pl/news.asp?ID=98812 (dostęp: 30.11.2016).

${ }^{4}$ Szerzej na ten temat, przywołując też wspomniane przykłady z LOTRO, zob. R. Kochanowicz, The Lord of the Rings Online - Tolkienowska opowieść transmodalna, [w:] Między literatura a filmem - Kulturowe aspekty ekranizacji prozy J.R.R. Tolkiena. Eseje i studia. red. M. Michalski, E. Kledzik, Poznań 2018, s. 123-138. 
prawie przez Ścieżkę Umarłych. Wydarzenia związane z Szarą Drużyną rozgrywają się w Enedwaith, ale poszczególnych Strażników Północy prowadzony przez gracza awatar spotyka w najróżniejszych miejscach. Niektórzy, jak Amlan w Bree, zlecają mu określone zadania, inni są handlarzami, a jeszcze inni, jak Halbarad, także towarzyszami broni. Do tej pory (gra ciągle jest rozszerzana) — można doliczyć się ponad 60 nazwanych Strażników Północy, którzy są ważnym elementem warstwy fabularnej współtworzonej opowieści, a związane z nimi wątki funkcjonują jako jedna z klamer scalających tematyczne i kompozycyjne kontury całego cyfrowego świata. Jednym z zaplanowanych dla gracza zadań jest bowiem prześledzenie szlaku, którym zmierzała Szara Drużyna w kierunku Rohanu, i tym samym poznanie losu poszczególnych Dúnedainów. Owe rozwijające Tolkienowski świat motywy są w grze istotnym elementem lore, który również jest przez fanów analizowany ${ }^{5}$.

Dbałość o konwencję charakteryzuje jednak nie tylko zabiegi zespołów profesjonalnych, lecz także pojedynczych graczy — moderów, którzy określają swoje, często niewielkie, amatorskie modyfikacje gier (w tym rzecz jasna także polskiego Wiedźmina 3) jako lore-friendly (na przykład Lore-friendly Witchers at The Witcher 3 Nexus - Mods and community), co jest jednoznacznym komunikatem, że dany mod wpisuje się w kultywowaną konwencję: „This modification series aims for a more lore-friendly appearance of Geralt and the other witchers. By »lore « I mean the previous games, references in the current game itself and Andrzej Sapkowski's books" 6 .

\section{Lore oryginalne}

Nieco inaczej omawiane zjawisko prezentuje się w wypadku gier, których twórcy oferują miłośnikom bardziej lub mniej oryginalną, autorską propozycję nowego lore $^{7}$. Wypada przy tej okazji zaakcentować, że pod względem zabiegów światotwórczych przemysł gier komputerowych stał się dziś jednym z podstawowych obszarów działalności, która choć w dużej mierze pozostaje koniunkturalna, to w jeszcze większej okazuje się kulturotwórcza. Nie wszystkie jednak propozycje komputerowych programistów i scenarzystów przetrwały próbę czasu. Największym uznaniem wśród fanów cieszą się bowiem tylko te tytuły, których twórcy nie poprzestali na sztampowym, szczątkowym zarysie fabuły, ale rozwinęli propozycje nowych, fantastycznych przygód w skomplikowany świat dorównujący niekiedy swymi rozmiarami (choć niekoniecznie kolorytem) wspomnianym pomysłom Lucasa czy Tolkiena. Trudno zatem się dziwić, że najbardziej ekspansywne oryginalne lore w komputerowych produkcjach bywa konkretyzowane w wieloletnich se-

5 Por. The members of the Grey Company and their fates?, https://www.lotro.com/forums/ showthread.php?495679-The-members-of-the-Grey-Company-and-their-fates (dostęp: 30.11.2016).

${ }^{6}$ Por. Lore-friendly Witchers, http://www.nexusmods.com/witcher3/mods/390/? (dostęp: 30.11. 2016).

7 Por. R. Whitaker, 8 Games with Great Original Lore, http://www.escapistmagazine.com/articles/ view/features/galleryoftheday/13732-8-Games-with-the-Best-Original-Lore (dostęp: 30.11. 2016). 
riach gier, z których najstarsze - na przykład „World of Warcraft” czy „The Elder Scrolls" - są obecne w masowej kulturze od blisko dwudziestu lat.

Światotwórcze zabiegi programistów podlegają bowiem tej samej „logice rozrostu" - od fragmentu aż po ogromny, otwarty i wielowarstwowy świat - która charakteryzuje twórczość autorów fantastyki — pisarzy i filmowców. Ekspansywny charakter lore z kolei wiąże się rzecz jasna z przenikaniem motywów z gier komputerowych do innych mediów, na przykład książek czy filmów ${ }^{8}$. I także w tym wypadku fani zwracają szczególną uwagę na zgodność owych nawiązań z konkretyzacjami zawartymi w grze i stanowiącymi — ich zdaniem niepodważalny fundament tożsamości fantastycznego uniwersum. Odsłaniają to też wyraźnie żywiołowe dyskusje graczy dotyczące modyfikacji (na przykład serii „Gothic”), gdyż — jak się okazuje — w dywagacjach na temat oryginalnego lore z gier komputerowych liczy się każdy, nawet najmniejszy szczegół:

A np reszta rzeczy w global, gdzie masz powiedziane że nie było mrocznych w khorinis?? NIGDZIE. Dlatego to jest też unlore ale nie tak bardzo jak np dodanie uriziela. Według ciebie dodanie jednej więcej rośliny to UNLORE bo PB nie dodała tej rośliny w grze Przestań patrzeć NA LORE KOMPLETNYM I UNLORE KOMPLENTYM bo jest też środek ${ }^{9}$.

Fanowski dyskurs, obejmując takie zagadnienia, jak:

— klasyfikacje — rozróżnienie na „kanon”/,apokryf” (wersja podstawowa/ wersje nawiązujące),

— rozstrzygnięcia - lore/unlore (odrzucane modyfikacje),

- ewolucje - akceptowane transgresje/uzupełnienia,

pozostaje zatem świadectwem tego, jak niezwykle ważne jest lore dla fanowskiej recepcji produktu (gry). To swego rodzaju zbiór zasad, które muszą być przestrzegane, i motywów, które muszą lub nie mogą się pojawić. Towarzyszy temu przywiązanie graczy do „kanonu” i jego interpretacji („tradycja”) oraz swoista „negacja” podejścia postmodernistycznego i tak zwanych wariacji na temat (o ile nie mają one celowo humorystycznego przeznaczenia).

\section{Lore — ,indeksykalność znaczenia"}

Nie ulega wątpliwości, że lore w grach komputerowych — jako efekt światotwórczych zabiegów programistów - niekiedy przesądza o sukcesie danej produkcji na rynku. Równocześnie trudno nie zauważyć, że oryginalne propozycje twórców są w dużym stopniu kompilacjami funkcjonujących w kulturze wątków i motywów. O oryginalności lore w danej grze czy też o jego przynależności do

8 Wypada wspomnieć choćby powieści Grega Keyesa rozwijające pomysły programistów z Bethesdy i realia świata Tamriel z serii „The Elder Scrolls” czy film Ducana Jonesa Warcraft: Poczatek (Warcraft: The Beginning, Chiny-Japonia-Kanada-USA 2016).

${ }^{9}$ Por. Dyskusje na temat lore, http://themodders.org/index.php?topic=22447.0 (dostęp: 30.11 . 2016). Zachowano pisownię oryginalną. 
znanego już fantastycznego świata decydują zatem te elementy, które albo są częścią wspólną dla nawiązania i „kanonu” (lore zapożyczone), albo wskazują na całkowicie odmienny charakter ukazanego w grze świata (lore oryginalne). Istotą lore pozostaje jednak nie tyle sam wykorzystany motyw, ile przede wszystkim kontekst, w którym go użyto (swoista ,indeksykalność”).

Widać to szczególnie wyraźnie podczas analizy w grach podejmujących konwencję fantasy popularnych motywów i postaci, na przykład orka. Jest ona niezwykle ważna dla lore w takich tytułach, jak LOTRO, WOW oraz serie „Gothic” czy „The Elder Scrolls". Trzeba przy tym zaznaczyć, że wyszczególnione produkcje należą do czołówki gier komputerowych, a zastosowane w nich rozwiązania i mechanika od wielu lat wyznaczają trendy i decydują o kierunku rozwoju rozrywki cyfrowej. We wszystkich z nich pojawią się Orki, co z jednej strony świadczy o ustalonej popularności motywu w konwencji fantasy, a z drugiej — o tym, że nawet wykorzystywanie zbliżonych audiowizualnych konkretyzacji przywołanej postaci nie decyduje o jej przynależności do jednego świata ukazanego w grach (zob. ilustracje 2-5) ${ }^{10}$.

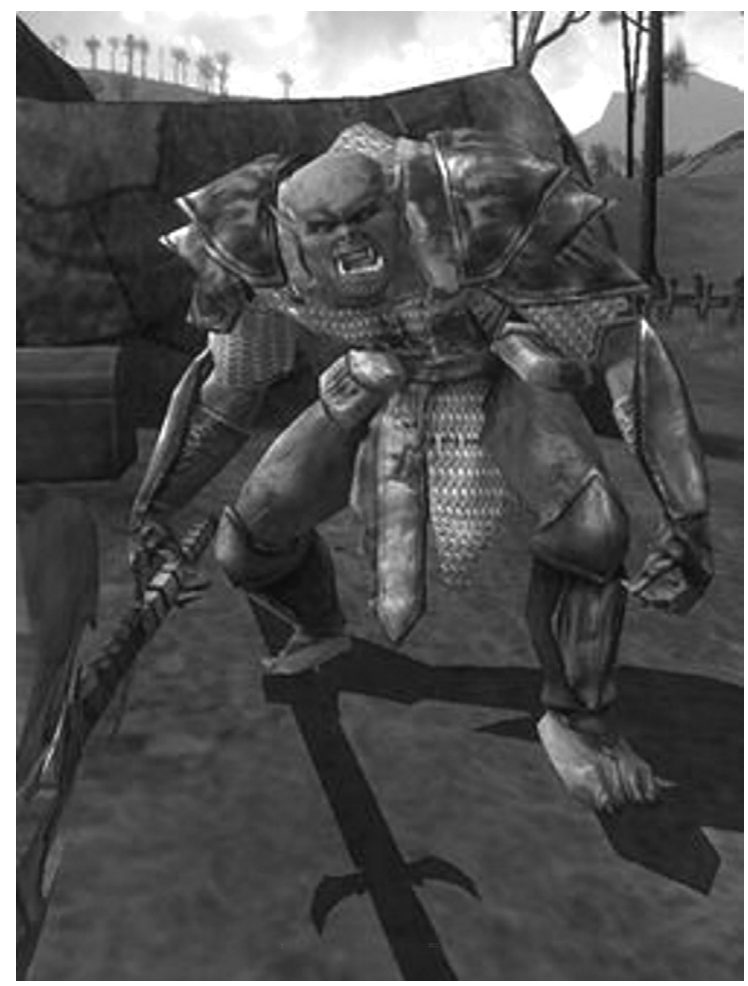

Ilustracja 2. Zrzut ekranu przedstawiającego orka w LOTRO

Źródło: https://lotro-wiki.com/index.php/Orcs (dostęp: 29.03.2018).

10 Por. Orcs, https://lotro-wiki.com/index.php/Orcs (dostęp: 29.03.2018); Skyrim - Ork (Orc), http://www.morrowind.pl/skyrim/rasy/ork (dostęp: 30.11.2016). 


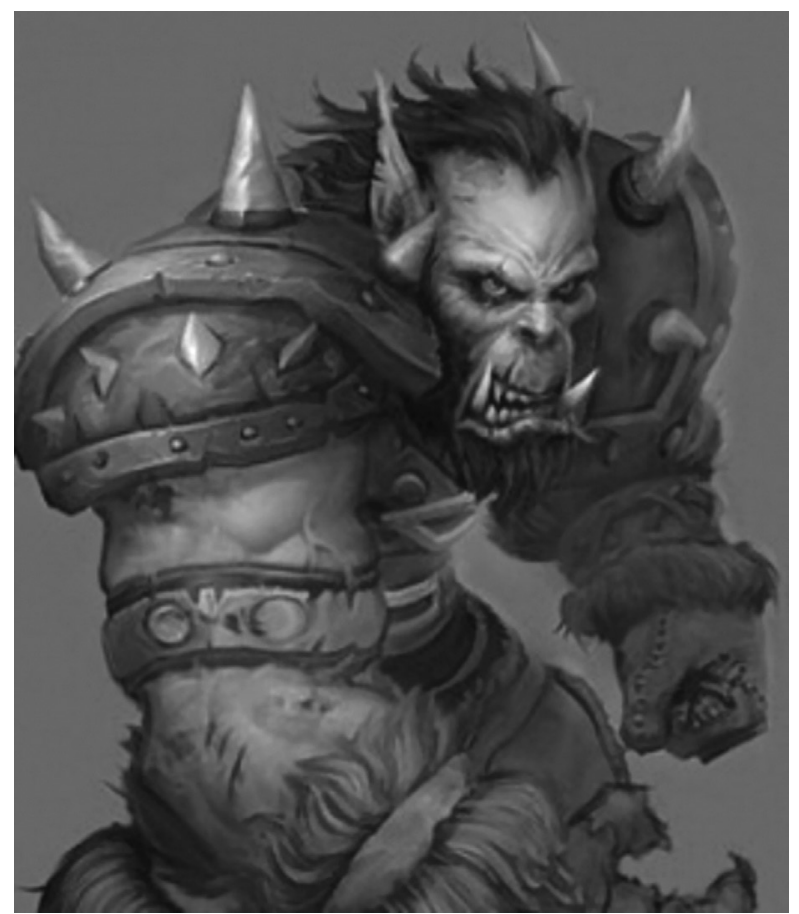

Ilustracja 3. Zrzut ekranu przedstawiającego orka w WOW

Źródło: https://wow.gamepedia.com/Orc_(playable) (dostęp: 15.04.2018).

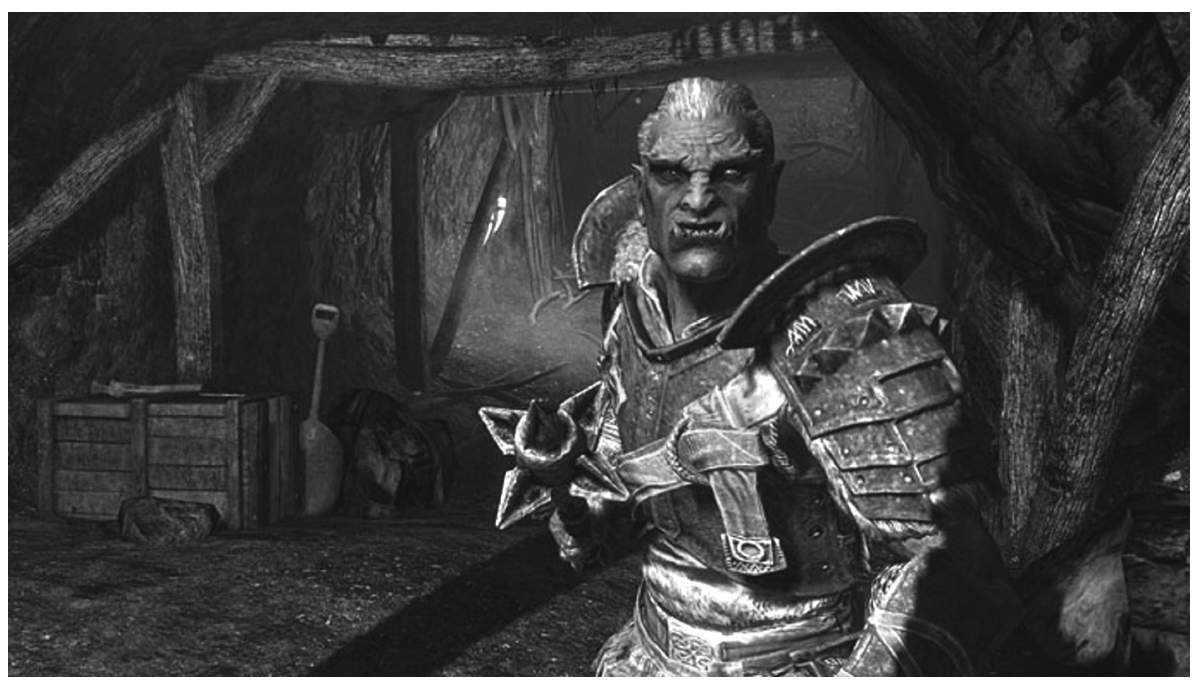

Ilustracja 4. Zrzut ekranu przedstawiającego orka w grze The Elder Skrolls V: Skyrim Źródło: http://www.morrowind.pl/skyrim/rasy/ork (dostęp: 30.11.2016) 


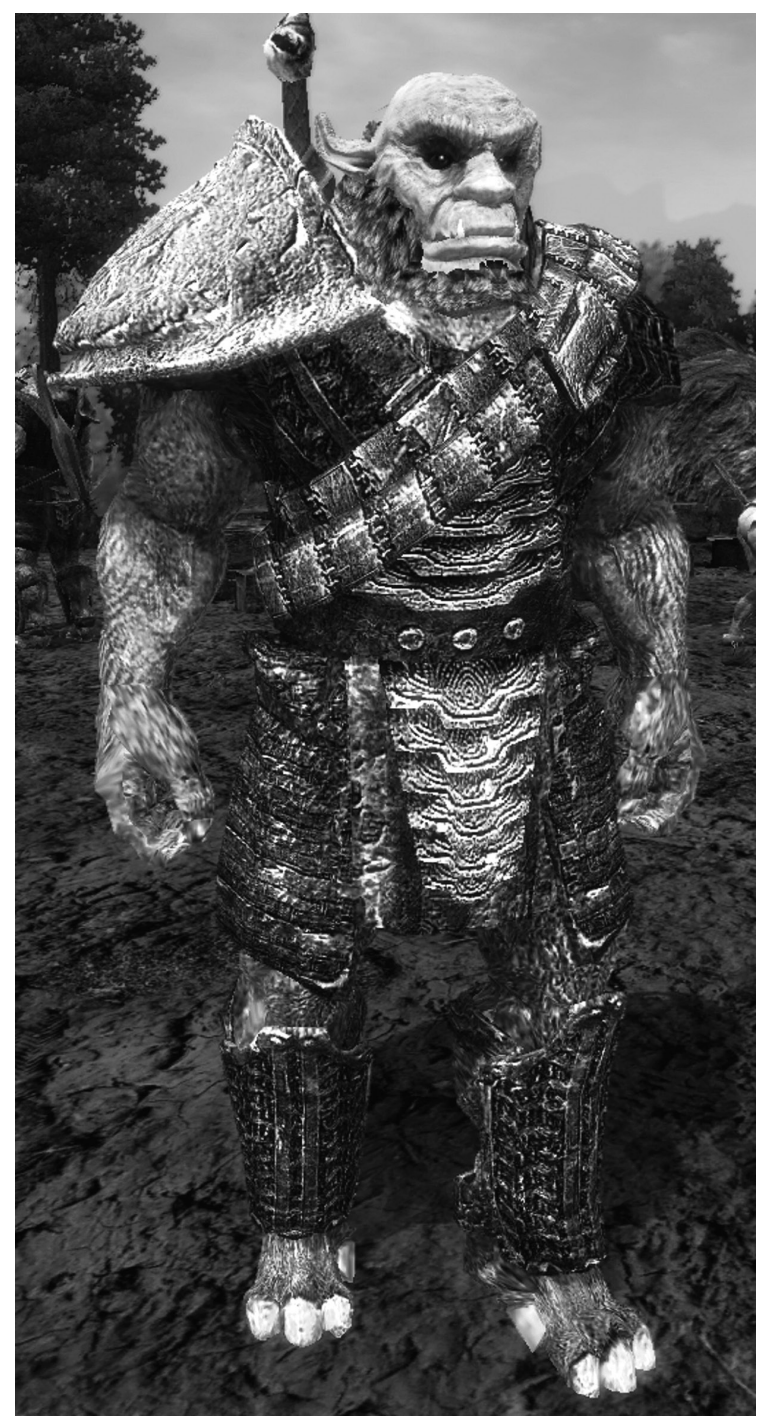

Ilustracja 5. Zrzut ekranu przedstawiającego orka w grze Gothic

Źródło: http://pl.gothic.wikia.com/wiki/Plik:Tempeck_(Content_Mod_2.2)_(by_Kubar906).png (dostęp: 30.11.2016).

Quasi-średniowieczny rynsztunek, duże i wystające dolne kły, „małpia” fizjonomia to podstawowe atrybuty wizerunku orka, ale ukazane podobieństwo nie definiuje tego samego przekazu i znaczenia. Orki w LOTRO są audiowizualną konkretyzacją pomysłów Tolkienowskich, w WOW współtworzą Hordę, w „Gothicu” służą złemu Beliarowi, a w „The Elder Scrolls” stanowią po prostu równorzędną i zbliżoną do ludzkiej inteligentną rasę. Barbarzyński charakter postaci — choć w różnym nasileniu pojawiający się we wszystkich tytułach — też 
nie określa przynależności do tego samego systemu. Dla graczy-użytkowników-współtwórców istotne pozostaje nie to, co upodabnia poszczególne konkretyzacje, ale przede wszystkim to wszystko, co je różnicuje. Innymi słowy w celu postrzegania odrębności danego fantastycznego uniwersum w grze komputerowej konieczne jest właśnie lore jako kontekst — odmienny, dystynktywny system.

\section{Lore - system i supersystem}

O ile twórcy gier rozwijając cudze pomysły (lore zapożyczone), korzystają już z gotowego zestawu motywów, a fani poniekąd badają — jak na przykład w przypadku Wiedźmina — zgodność literackiego „kanonu” z cyfrowym „apokryfem”, o tyle propozycje oryginalnych, nowych światów w grach niejako same z siebie domagają się porządkowania i kategoryzowania. Także w tym wypadku powstają zatem zbudowane na podstawie Wikipedii encyklopedie, bestiariusze, schematy, zestawienia i charakterystyki, scalające i systematyzujące to wszystko, co w grze zostało zatomizowane $\mathrm{w}$ ramach rozgrywki, a pozostaje niezbywalne do odczytania i zinterpretowania zaproponowanego uniwersum. Multimodalny wymiar cyfrowych tekstów kultury, w których istotne na przykład dla zrozumienia fabuły informacje dostarczane są grającemu w przeróżny sposób, powoduje, że proces systematyzacji realizowany — najczęściej w mediach społecznościowych — jest de facto powrotem do schematu wyjściowego (niejako draftu), scenariusza gry, który dynamizuje się podczas rozgrywki. Ma on charakter improwizowany, co powoduje, że w bardziej rozbudowanych cyfrowych światach, jak na przykład uniwersum „Warcrafta", grającemu trudno od razu odczytać i zinterpretować, czy po prostu zrozumieć, wszystkie niuanse świata, w którym porusza się jego awatar. Swoiste, niejako encyklopedyczne rekonstrukcje pomagają zatem w tematycznym rozpoznaniu i nawigacji, a równocześnie demaskują systemowość lore. Widać to bardzo wyraźnie choćby na przykładzie dokładnie przez graczy rozrysowanego drzewa ukazującego skomplikowane dzieje elfów w świecie „World of Warcraft” (zob. ilustracja 6).

Tak rozumiana systematyzacja, przyjmująca niekiedy formę precyzyjnie dopracowanych kodyfikacji, leksykonów, spisów, wykresów itp., determinuje rzecz jasna ekspansywny charakter lore — czego notabene przywołana produkcja Blizzarda też jest dobitnym przykładem. Zapoczątkowany w 1994 roku rozwój fantastycznego świata „Warcrafta” stał się bowiem procesem, który wygenerował zjawisko będące dokładnie tym, co Marsha Kinder określa mianem „supersystemu rozrywkowego" 11 . Fantastyczne i usystematyzowane lore w serii gier Blizzarda, a szczególnie ujęte w odsłonie MMORPG, czyli w WOW, światotwórcze

11 Por. M. Kinder, Playing with Power in Movies, Television, and Video Games. From Muppet Babies to Teenage Mutant Ninja Turtles, Berkeley 1991; oraz Z. Wałaszewski, Wiedźmin: pierwszy polski supersystem rozrywkowy, [w:] Obraz literatury w komunikacji społecznej po roku '89, red. A. Werner, T. Żukowski, Warszawa 2013, s. 128-129. 


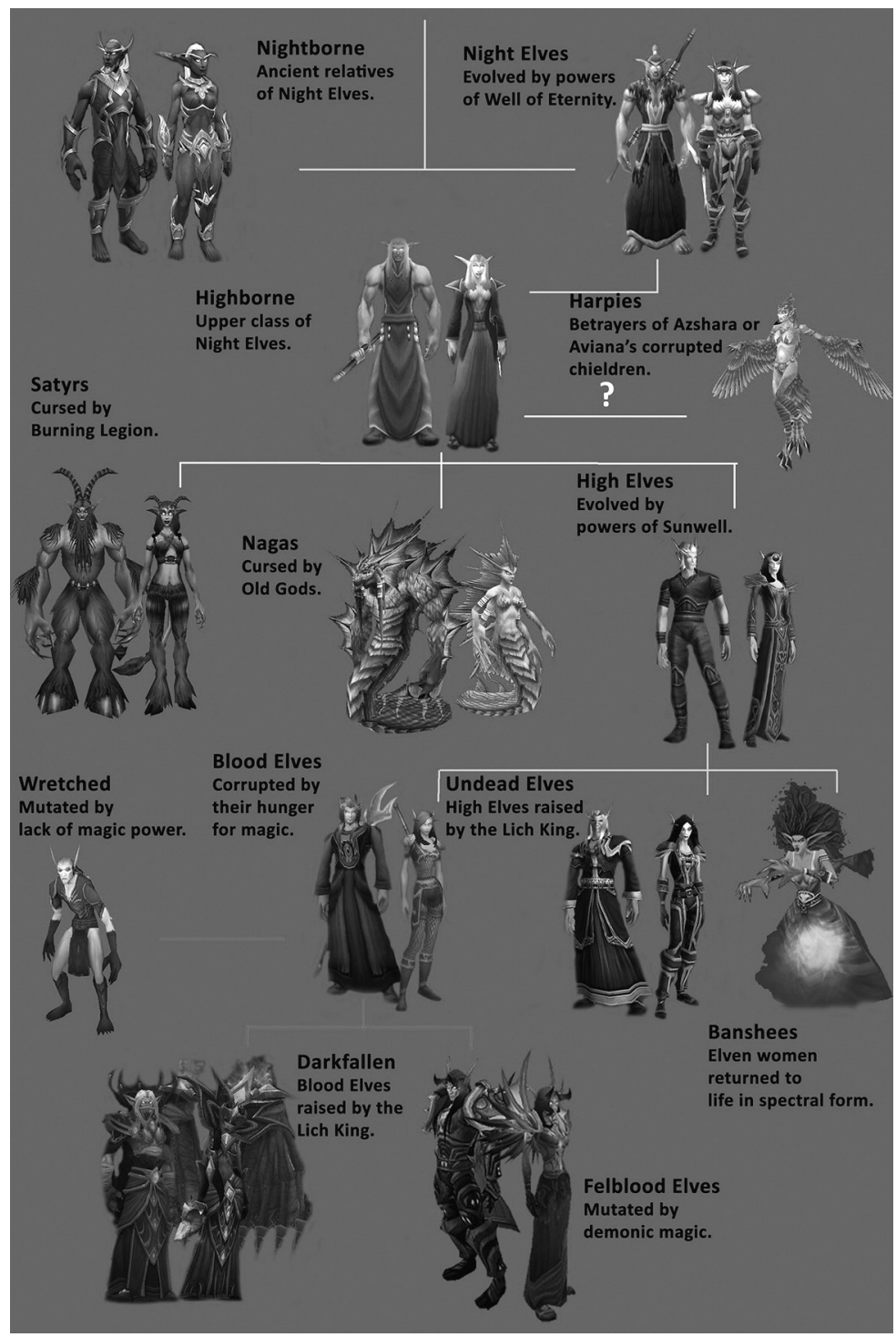

Ilustracja 6. Zrzut ekranu przedstawiającego „Drzewo elfów” w WOW

Źródło: http://wowwiki.wikia.com/wiki/File:Anotherelvenfamilytree.jpg (dostęp: 30.11.2016).

pomysły i zabiegi twórców cyfrowej produkcji, utrwaliły w masowej kulturze markę firmy oraz zaistniały w ramach transmedialnych konkretyzacji. Nie chodzi tu jednak wyłącznie o scharakteryzowaną przez Henry’ego Jenkinsa „opowieść transmedialną", ale o cały transmedialny świat, którego fundamentem pozostaje zaproponowane przez programistów oryginalne lore ${ }^{12}$. Trudna do zliczenia licz-

12 Por. H. Jenkins, Kultura konwergencji. Zderzenie starych i nowych mediów, przeł. M. Bernatowicz, M. Filiciak, Warszawa 2007. 
ba nawiązań (obejmujących nie tylko realizacje filmowe - w tym amatorskie, youtube'owe machinimy — książki, opowiadania, fan fiction, lecz także tak zwane produkty figuratywne) demaskuje zarówno specyfikę kultury uczestnictwa, jak i systemowość koniunkturalnego wymiaru współczesnej popkultury:
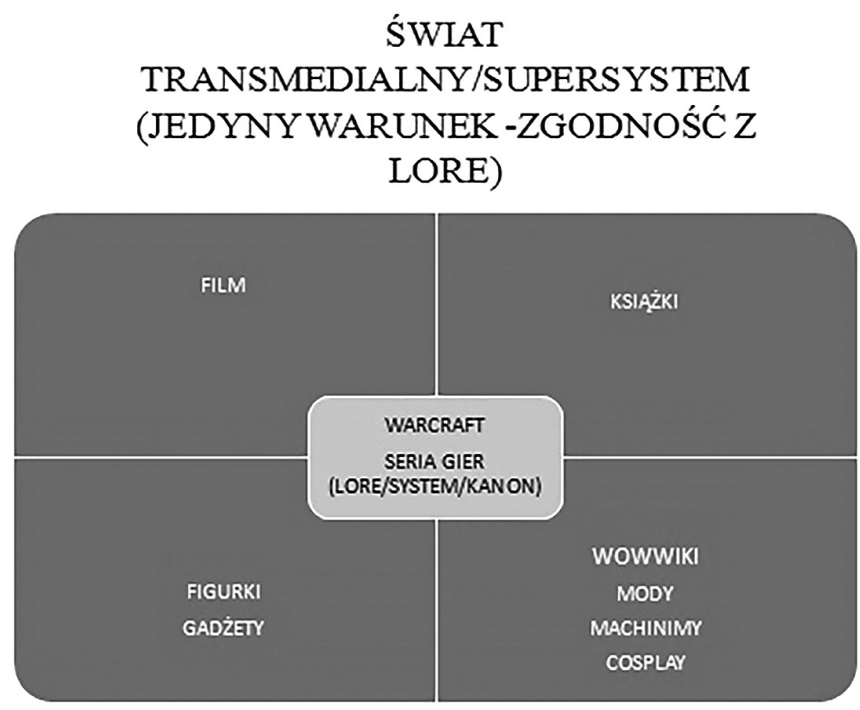

Schemat 2

Źródło: opracowanie własne.

Funkcjonowanie tak rozumianego transmedialnego świata pokazuje też de facto istotę supersystemu rozrywkowego, który wykracza poza strukturę systemu macierzystego (tematycznego kanonu, pierwotnego medium itp.), równocześnie nie tracąc jego cech dystynktywnych, takich jak konwencjonalnie uwarunkowana „tradycja” (lore) w wypadku gier.

\section{Lore - podstawa, dodatek, "granice". Podsumowanie}

Samo stwierdzenie faktu funkcjonowania supersystemu nie określa jednak kierunków rozwoju, charakteru ekspansji i istoty zachodzącym w nich przemian. W przypadku gier komputerowych jego podstawowe cechy można jednak opisać, odwołując się także bezpośrednio do Ogólnej teorii systemów Ludwika von Bertalanffy'ego, a w szczególności do zaprezentowanej przezeń specyfiki „systemu otwartego”:

1. wymiana składników z otoczeniem [transmedialność - R.K.],

2. samoregulacja [lore/unlore - R.K.], 
3. utrzymywanie stanu stabilności przy zasilaniu w energię z zewnątrz [zgodność z „tradycją" - R.K.],

4. ekwifinalność — stan końcowy [,supersystemu” — R.K.] może być osiągnięty z wielu stanów początkowych i w rożny sposób [gra, książka, film itp. - R.K.] ${ }^{13}$.

Przywołany wcześniej przypadek „Warcrafta” doskonale pokazuje, w jaki sposób lore z gry komputerowej może wpływać na powstanie supersystemu rozrywkowego i staje się jego podstawą. $Z$ kolei lore obejmujące przygody cyfrowego wiedźmina czy rozszerzone dzieje Szarej Drużyny z LOTRO pozostają przykładem dodatkowych nawiązań, które wpisują się w obowiązującą konwencję i jako takie poszerzają granice już zastanego supersystemu. Trzeba jednak przy tej okazji zaznaczyć, że zbyt daleko idąca modyfikacja może niekiedy owe granice naruszyć i tym samym albo zostać przez fanów odrzucona, co widać najczęściej na przykładzie krytykowanych modów, albo też się zautonomizować zapoczątkowując zupełnie nowy system (nawet w ramach zbliżonej mechaniki gry). Przykładem tego drugiego wariantu jest geneza League of Legends (2009, producent i wydawca: Riot Games) — gry, która — jak powszechnie wiadomo - powstała na kanwie jednego z modów (Defense of the Ancients) do produkcji Blizzarda Warcraft III: Frozen Throne (2003, wydawca: Blizzard Entertainment, wydawca polski: CD Projekt) i stała się w Stanach Zjednoczonych oficjalnym e-sportem, oferując graczom nie tylko związane z rywalizacją emocje, lecz także nowe lore ${ }^{14}$. Takie wzajemne przenikania, ewolucje i modyfikacje lore $\mathrm{z}$ gier komputerowych nieuchronnie kojarzą się - oczywiście z zachowaniem wszelkich różnic i proporcji - z tym, co omawia w swoich pracach Julien d'Huy. Francuski historyk, korzystając $\mathrm{z}$ analizy filogenetycznej, śledzi ewolucję mitów, „by wykazać, jak i dlaczego mity i opowieści zmieniają się w czasie"15. I w tym ujęciu wyłaniają się dwie podstawowe kwestie dotyczące możliwych badań związanych z lore.

Pierwsza dotyczy tego, że lore jako system również ewoluuje i stanowi poniekąd swoistą namiastkę „mitologii naszych czasów”. Ciekawostką zresztą jest to, że podobnie jak w wypadku mitów, które opisuje Francuz, o rozpoznawalności czy też tożsamości danej opowieści i lore jako systemu — realizowanego w różnych warunkach — decydują także „wspólne motywy i elementy narracji”. Przywiązanie graczy do lore jako „tradycji” potęguje jeszcze ten aspekt, dostarczając równocześnie informacji, które z elementów, motywów, fragmentów są

13 Por. L. von Bertalanffy, Ogólna teoria systemów, Warszawa 1984, s. 70-79; oraz E. Wołoszyn, Koncepcja systemu otwartego Ludwiga von Bertalanffy'ego, „Filozofia Nauki” 5, 1997, nr 1, s. 136.

14 Por. T. Wrzesień, Gracze w League of Legends to oficjalnie sportowcy, USA stoi otworem, https://www.dobreprogramy.pl/Gracze-w-League-of-Legends-to-oficjalnie-sportowcy-USA-stoi-otworem,News,42679.html (dostęp: 30.11.2016); oraz PefriX, Lore - złe dobrego poczatki, http://mmo24.pl/gry/lol/pbe-lol/lore-zle-dobrego-poczatki/ (dostęp: 30.11.2016).

15 Por. J. d'Huy, Scientists Trace Society's Myths to Primordial Origins, https://www.scientificamerican.com/article/scientists-trace-society-rsquo-s-myths-to-primordial-origins/ (dostęp: 29.03.2018). 
przez społeczność uznane za konstytutywne i niezbywalne - inwariantne, a które mogą być modyfikowane bądź w kolejnych reaktualizacjach po prostu znikają. Przywołany wcześniej przykład dyskusji graczy na temat lore w „Gothicu” pokazuje także, iż nawet dodatek w postaci ,jednej rośliny” może wywołać daleko idące kontrowersje, a nie zabrakło i głosów, że w ogóle każdy amatorski mod jest naruszeniem ,kanonu” i tym samym pozostaje unlore $^{16}$.

Kwestia druga z kolei wiąże się z tym, że nawet lore oryginalne, które pojawia się w grach, jest zwykle — o czym wcześniej wspomniano — de facto kompilacją funkcjonujących już w kulturze wątków i motywów. Co więcej, ich fantastyczny charakter często wskazuje jednoznacznie na baśniową i mitologiczną proweniencję, a tym samym lore staje się niejako - w ograniczonym rzecz jasna zakresie - świadectwem kolejnego etapu analizowanej przez francuskiego historyka ewolucji. Badacza interesuje co prawda najbardziej — jak sam pisze — identyfikacja prehistorycznych protomitów, dzięki którym można by próbować zrozumieć ludzkich przodków i to z czasów, gdy Homo sapiens nie był odosobnionym hominidem. W wypadku badań związanych z lore zachodziłaby odwrotna sytuacja. Pogłębiona analiza — przy założeniu, że gry mają zasięg globalny - mogłaby wykazać, jakie fragmenty z owych protomitów człowiek żyjący w czasach opanowanych przez technologię cyfrową wciąż utrwala i reaktualizuje w supersystemach rozrywkowych i dlaczego właśnie te, a nie inne.

\section{Bibliografia}

\section{Opracowania}

Bertalanffy L. von, Ogólna teoria systemów, przeł. E. Woydyłło-Woźniak, PWN, Warszawa 1984. Jenkins H., Kultura konwergencji. Zderzenie starych i nowych mediów, przeł. M. Bernatowicz, M. Filiciak, Wydawnictwo Akademickie i Profesjonalne, Warszawa 2007.

Kinder M., Playing with Power in Movies, Television, and Video Games: From Muppet Babies to Teenage Mutant Ninja Turtles, University of California Press, Berkeley 1991.

Kochanowicz R., The Lord of the Rings Online - Tolkienowska opowieść transmodalna, [w:] Między literatura a filmem - Kulturowe aspekty ekranizacji prozy J.R.R. Tolkiena. Eseje i studia. red. M. Michalski, E. Kledzik, Instytut Historii UAM, Poznań 2018, s. 123-138.

Netlor. Wiedza cyfrowych tubylców, red. P. Grochowski, Wydawnictwo Naukowe UMK, Toruń 2013.

Wałaszewski Z., Wiedźmin: pierwszy polski supersystem rozrywkowy, [w:] Obraz literatury w komunikacji spotecznej po roku '89, red. A. Werner, T. Żukowski, Wydawnictwo IBL PAN, Warszawa 2013, s. 126-154.

Wołoszyn E., Koncepcja systemu otwartego Ludwiga von Bertalanffy'ego, „Filozofia Nauki” 5, 1997, nr 1, s. 134-139.

16 Dyskusje na temat lore... 


\section{Filmografia}

Warcraft: Początek (Warcraft: The Beginning), reż. D. Jones, Chiny-Japonia-Kanada-USA 2016.

\section{Gry}

Bethesda Game Studio, The Elder Scrolls (seria gier), wyd. Bethesda Softworks, 1994-2012.

Bethesda Game Studio, Fallout III, wyd. Bethesda Softworks, 2008.

Bethesda Game Studio, Fallout IV, wyd. Bethesda Softworks, 2015.

Blizzard Entertainment, Warcraft III: Frozen Throne, wyd. Blizzard Entertainment, wyd. polski: CD Projekt, 2003.

BioWare, Star Wars: The Old Republic, wyd. LucasArts, Electronic Arts Inc., 2011.

CD Projekt RED, Wiedźmin, wyd. Atari/Infogrames, wyd. polski: CD Projekt, 2007.

CD Projekt RED, Wiedźmin 3: Dziki Gon, wyd. Bandai Namco Entertainment, wyd. polski: CD Projekt, 2015.

Funcom, Age of Conan, wyd. Eidos, dystrybutor: CD Projekt, 2008.

Interplay Productions, Fallout, wyd. Interplay Productions, 1997.

Piranha Bytes, Gothic, wyd. Xicat, 2001.

Riot Games, League of Legends, wyd. Riot Games, 2009.

Turbine Inc, Lord of the Rings Online, wyd. Turbine Inc et al., 2007.

\section{Źródla internetowe}

Draug, Gorzkie żale nad fabuła Wiedźmina 3 - tak dobra na tle innych gier, tak złą na tle ksią̇ek, https://gameplay.pl/news.asp?ID=98812 (dostęp: 30.11.2016).

Dyskusje na temat lore, http://themodders.org/index.php?topic=22447.0 (dostęp: 30.11.2016).

Hobbit Warden - against lore?, https://www.lotro.com/forums/showthread.php?480688-HobbitWarden-against-lore (dostęp: 30.11.2016).

Huy J. d', Scientists Trace Society's Myths to Primordial Origins, https://www.scientificamerican.com/ article/scientists-trace-society-rsquo-s-myths-to-primordial-origins/ (dostęp: 29.03.2018).

Lore-friendly Witchers, http://www.nexusmods.com/witcher3/mods/390/? (dostęp: 30.11.2016).

The members of the Grey Company and their fates?, https://www.lotro.com/forums/showthread. php?495679-The-members-of-the-Grey-Company-and-their-fates (dostęp: 30.11.2016).

Orcs, https://lotro-wiki.com/index.php/Orcs (dostęp: 29.03.2018).

PefriX, Lore - zle dobrego poczatki, http://mmo24.pl/gry/lol/pbe-lol/lore-zle-dobrego-poczatki/ (dostęp: 30.11.2016).

Skyrim - Ork (Orc), http://www.morrowind.pl/skyrim/rasy/ork (dostęp: 30.11.2016).

Whitaker R., 8 Games with Great Original Lore, http://www.escapistmagazine.com/articles/view/ features/galleryoftheday/13732-8-Games-with-the-Best-Original-Lore (dostęp: 30.11.2016).

Wrzesień T., Gracze w League of Legends to oficjalnie sportowcy, USA stoi otworem, https:// www.dobreprogramy.pl/Gracze-w-League-of-Legends-to-oficjalnie-sportowcy-USA-stoi-otworem,News, 42679.html (dostęp: 30.11.2016). 


\title{
Game lore - addition, a basis and the "border" of supersystems
}

\begin{abstract}
Summary
The term "game lore" does not have its exact equivalent in Polish. However, it remains an important manifestation of the reception of computer games. It is also an example of how computer games are initiated or supplemented by entertainment systems operating in the field of popular culture. Research on game lore can provide information that parts of the tradition of man living in times dominated by digital technology, continues to perpetuate and update, and why these, and not others. Basically, one can distinguish three main types of game lore. The first - as a complement to the entertainment superstructure - concerns cases when game developers reach the known universe (for example LOTRO) - and develop the ideas of the author (J.R.R. Tolkien). The second — as the basis of the new supersystem - is associated with the original ideas of programmers who create a new universe (for example, the Warcraft series, The Elder Scrolls). The third example - connected with the evolution of the new universe and the supersystem in new and autonomous lore (for example League of Legend).
\end{abstract}

